\title{
FATORES RELACIONADOS À CRIATIVIDADE NO INDIVÍDUO, EM GRUPOS E NO CONTEXO: UMA REVISÃO
}

\author{
Priscila Zavadil \\ Universidade Federal do Rio Grande do Sul \\ priscila.zavadil@ufrgs.br \\ Katja Tschimmel \\ Escola Superior de Artes e Design - ESAD Matosinhos, Portugal \\ katjatschimmel@esad.pt \\ Régio Pierre da Silva \\ Universidade Federal do Rio Grande do Sul \\ regio@ufrgs.br
}

Resumo: A criatividade projetual é uma capacidade determinante para a geração de ideias e novas soluções, através de um processo cognitivo individual, mas também de um processo de design e criativo que compreende diversos atores trabalhando em conjunto, inseridos em um contexto social. Muitas teorias relatam aspectos relevantes para a criatividade no indivíduo e no contexto em que se insere, algumas trazendo modelos de interações entre esses componentes. Entretanto, diante da diversidade de teorias e de variáveis que podem afetar a criatividade, este artigo visa identificar os principais fatores que influenciam a criatividade e como se relacionam entre o indivíduo e este inserido em grupos de projeto e em determinado contexto ambiental. Para isso, realizou-se uma revisão de literatura sobre os aspectos da criatividade no indivíduo e no contexto ambiental, incluindo abordagens cognitivas e sociais da criatividade. A partir dessa revisão, desenhou-se um modelo teórico com o mapeamento desses principais fatores e suas relações. Com base na literatura, pode-se verificar que a motivação é o elemento-chave que inter-relaciona os demais fatores no indivíduo, grupo e contexto.

Palavras-chave: indivíduo criativo, criatividade social, design.

Abstract: Design creativity is not only a crucial ability to generate ideas and new solutions through an individual cognitive process, but also a design and creative process that can include several participants working together, embedded in a social context. Many theories report features relevant to the creativity of the individual and the context in which it operates, bringing rise to some models of interactions between these components. However, given the diversity of theories and variables that can affect creativity, this paper aims to identify the main factors influencing creativity and how they relate to the individual, and insert this into project groups, and in particular 
an environmental context. For this, we carried out a literature review on aspects of creativity of the individual and in the wider context, including cognitive and social approaches to creativity. From this review, we drew up a theoretical model with the mapping of these key factors and their relationships. Based on the literature, it can be seen that motivation is the key element that interrelates the other factors in the individual, group and context.

Keywords: individual creativity, social creativity, design.

\section{INTRODUÇÃO}

Um dos conceitos mais explorados e aceitos sobre a criatividade é o que a define como a produção de novas ideias ou soluções, que sejam úteis e apropriadas ao contexto, referindo-se tanto ao processo de geração de ideias ou resolução de problemas, quanto à ideia ou solução em si (AMABILE, 1983; HENESSEY, AMABILE, 2010; KLIJN, TOMIC, 2010; LUBART, 2007; STERNBERG, 1988; WOODMAN et al, 1993). Especificamente, a criatividade projetual é definida como um processo pelo qual um agente utiliza sua habilidade para gerar ideias, soluções ou produtos que são novos e úteis (SARKAR, CHAKRABARTI, 2008).

A criatividade é uma capacidade que todos os sistemas possuem para criar novas complexidades, reordenar e estruturar situações, produzindo novos pensamentos, processos, produtos, ideias, ou soluções (TSCHIMMEL, 2010). Somandose à definição de Sarkar e Chakrabarti (2008), assume-se que que esta capacidade envolve um processo, com relação à criatividade em design. Além disso, a criatividade se manifesta a partir das características dos indivíduos, do ambiente social e cultural o que inclui também os grupos e equipes - e, portanto, requer uma requer uma abordagem interdisciplinar e sistêmica (ALENCAR, FLEITH, 2003; TSCHIMMEL, 2010).

Desse modo, para compreender e propor formas de facilitar o processo criativo no design é necessário ter clareza sobre os fatores que interferem no pensamento criativo dos designers durante o processo projetual, e na criatividade enquanto capacidade sistêmica. Assim, esse artigo tem como objetivo identificar os fatores relacionados a criatividade e como se relacionam no que se refere ao indivíduo, ao grupo e ao contexto no qual se inserem. Para tanto, apresenta uma revisão de literatura sobre os aspectos da criatividade atrelados ao indivíduo e ao contexto ambiental, valendo-se de abordagens cognitivas e sociais da criatividade. A partir da revisão realizada, apresenta-se um modelo teórico com o mapeamento desses fatores e relações. A sessão final do artigo discute ainda alguns aspectos relacionados ao modelo, sua possível contribuição e apresenta a continuidade da investigação.

\section{A CRIATIVIDADE NO INDIVÍDUO}

Embora atualmente se compreenda o papel do contexto e dos fatores situacionais para a criatividade, grande parte dos estudos focam nas características dos indivíduos criativos e concordam que são necessários alguns aspectos, como: fluência; flexibilidade; originalidade; e capacidade de elaboração de ideias (GUILFORD, 1967; KNELLER, 1978; KOWALTOWSKI et al, 2010; MARÍN IBAÑEZ, DE LA TORRE, 1991). 
A fluência se refere à capacidade de gerar mais ideias sobre um assunto, buscando a multiplicidade de respostas ou soluções para um mesmo problema (GUILFORD, 1967; KNELLER, 1978; MARÍN IBAÑEZ, DE LA TORRE, 1991).

A flexibilidade trata da capacidade de tentar diferentes abordagens e alterar o pensamento, rompendo com padrões tradicionais estabelecidos, a fim de visualizar determinado assunto sob diferentes pontos de vista (GUILFORD, 1967; KLAUSEN, 2010; KNELLER, 1978; MARÍN IBAÑEZ, DE LA TORRE, 1991).

A originalidade, considerada um dos indicadores mais importantes para a avaliação e definição da criatividade, compreende a capacidade de produzir ideias novas ou de resolver problemas de modo incomum (KNELLER, 1978). Envolve engenho, a capacidade expressiva e comunicativa e depende do contexto no qual o produto, ou a ideia, é desenvolvido (GUILFORD, 1967; MARÍN IBAÑEZ, DE LA TORRE, 1991).

A elaboração de ideias trata da capacidade de dar continuidade a determinada solução, aperfeiçoando-a e desenvolvendo-a. Consiste na facilidade em acrescentar detalhes a uma informação, a produtos ou esquemas, possibilitando que uma produção criativa progrida de um esboço até uma estrutura ou sistema organizado (ALENCAR, FLEITH, 2003; GUILFORD, 1967; KNELLER, 1971).

Além desses parâmetros, outras pesquisas identificam demais traços de personalidade importantes, como: intuição; persistência e dedicação; tolerância à ambiguidade, à desordem e à complexidade; espontaneidade; abertura a experiências; independência de julgamento; autoconfiança; habilidade de questionar e redefinir ideias; abertura a impulsos e fantasias (ALENCAR, FLEITH, 2003; FEIST, BARRON, 2003; GUILFORD, 1967; KNELLER, 1978; MACKINNON, 1965).

Ademais, muitos estudos sobre a criatividade se inter-relacionam com pesquisas sobre a inteligência humana. Apesar de não haver consenso absoluto, a maior parte das pesquisas sobre o tema concluíram que inteligência e criatividade, embora relacionadas, são capacidades distintas. A inteligência é associada com o processamento de informações, a resolução de problemas e ao raciocínio abstrato, enquanto a criatividade não significa apenas solucionar um problema, mas sim resolvêlo com originalidade e adequação (FEIST, BARRON, 2003; GUILFORD, 1950; STERNBERG, 2012).

Há ainda um aspecto importante relacionado ao indivíduo e que afeta diretamente a sua criatividade: a motivação intrínseca. Esse conceito se refere à satisfação pessoal na realização de uma tarefa, que deve ser envolvente e desafiadora. Também faz parte da personalidade do indivíduo, embora o ambiente social possa influenciar a motivação pessoal, e vice-versa (AMABILE, 1997).

Os fatores motivacionais externos, ao contrário, em alguns casos podem ser restritivos para a criatividade, quando limitam o modo como um trabalho é realizado, por exemplo. Entretanto, motivadores extrínsecos informacionais, como o reconhecimento, feedback sobre as competências, ou o fornecimento de informações para melhoria do processo, podem contribuir para a criatividade, sobretudo se a motivação inicial do indivíduo for alta (AMÁBILE, 1997).

Os elementos que formam a motivação intrínseca incluem: a autodeterminação; o sentimento de que as habilidades individuais estão sendo utilizadas e desenvolvidas; e os sentimentos positivos sobre o trabalho (AMABILE, FISCHER, 2009). Além disso, a motivação pessoal influencia e é influenciada pelo conhecimento existente (CHAKRABARTI, 2011). Embora algum conhecimento sobre o 
assunto em questão seja um fator que influencie a criatividade, a curiosidade também é um dos principais fatores motivacionais (SAUNDERS, GERO, 2001).

Uma das teorias que pode auxiliar a explorar o papel da motivação no processo e raciocínio projetual é a Regulatory Focus Theory (Teoria do Foco Regulatório) (HIGGINS, 1998). De acordo com essa abordagem, a motivação ocorre a fim de satisfazer a duas necessidades básicas: proporcionar prazer (foco na promoção) e evitar a dor (foco na prevenção). Em uma pesquisa sobre a relação entre o foco regulatório e o processo de design, os resultados indicaram uma maior propensão a aumentar o foco da promoção em fases do processo destinadas à compreensão do problema, à observação e à ideação, nas quais dominam tarefas novas e criativas. (CROWE, HIGGINS, 1997; KRÖPER et al, 2011).

Uma teoria que vem corroborar com essa visão é a experiência flow, segundo a qual a motivação de uma experiência reside nela mesma, que deve incluir elementos como: clareza nos objetivos; feedback imediato para cada ação; equilíbrio entre desafios e habilidades; ação e reflexão integradas; concentração na atividade; e disposição ao risco (CSIKSZENTMIHALYI, 2007).

Com isso, percebe-se que embora a motivação intrínseca seja uma característica individual, alguns fatores externos e a própria atividade na qual o sujeito está envolvido são influenciadores. Além disso, o trabalho em equipe e o ambiente também afetam a motivação pessoal, que por sua vez tem um papel decisivo no processo criativo de design (KRÖPER et al, 2011).

\section{A CRIATIVIDADE SOCIAL}

\subsection{Teorias e Modelos}

As teorias mais recentes assumem que é necessária uma visão contextual da criatividade, compreendendo o trabalho em equipe e o ambiente. Nessa visão, o contexto assume um papel fundamental para o estímulo do potencial criativo e modificar as suas condições pode ser um caminho para o desenvolvimento da criatividade (CSIKSZENTMIHALYI, 2007).

Dentre as principais referências nessa abordagem contextual, estão três modelos importantes: o Componential Model of Creativity (Modelo Componencial da Criatividade) (AMABILE, 1983; 1997); a Teoria do Investimento em Criatividade (STRERNBERG, 1988); e o Modelo Sistêmico da Criatividade (CSIKSZENTMIHALYI, 1988).

O Modelo Componencial da Criatividade considera que as habilidades do indivíduo são influenciadas pelo ambiente social, incluindo o domínio do conhecimento específico, as habilidades criativas e a motivação. As habilidades do domínio específico envolvem o conhecimento em determinada área e habilidades técnicas. As habilidades criativas incluem o estilo cognitivo apropriado, o conhecimento de estratégias para gerar novas ideias, e o estilo de trabalho. A motivação inclui as atitudes em relação a tarefa e as percepções da própria motivação para empreendê-la. Pode levar o indivíduo a buscar mais informações sobre a área estudada e, consequentemente, desenvolve as suas habilidades de domínio, além de levar ao desenvolvimento de novas estratégias criativas (AMABILE, 1983; 1997; ALENCAR, FLEITH, 2003).

Em convergência com este modelo, há também a Teoria do Investimento em Criatividade (STERNBERG, 1988; STERNBERG, LUBART, 1991; 1995), que indica seis 
fatores inter-relacionados: (i) inteligência; (ii) estilos intelectuais; (iii) conhecimento; (iv) personalidade; (v) motivação; e (vi) contexto ambiental.

De acordo com a Teoria do Investimento, a inteligência depende de três habilidades cognitivas: a capacidade sintética, analítica e a habilidade prática, contextual. Os estilos intelectuais se referem ao modo como o indivíduo utiliza ou explora a sua inteligência. O conhecimento, nesta abordagem, compreende o conhecimento explícito e o tácito. Os aspectos da personalidade dos indivíduos, já abordados neste trabalho, podem sofrer mudanças com o tempo e são influenciados pelas condições ambientais. Além disso, o outro fator individual considerado é a motivação, sobretudo com relação ao interesse pela realização do trabalho, embora tanto a motivação intrínseca quanto extrínseca sejam vistas como relevantes e combinam-se para estimular a criatividade (STERNBERG, LUBART, 1995).

O último componente da teoria de Sternberg e Lubart (1995) é o contexto ambiental, o qual pode afetar a produção criativa de três formas distintas: (i) o grau em que favorece a geração de ideias; (ii) a extensão em que estimula e apoia o desenvolvimento das ideias; e (iii) a avaliação que é realizada do produto ou solução gerada através do processo criativo.

Por fim há ainda a Perspectiva de Sistemas, de Csikszentmihalyi (1988). De acordo com essa teoria, a criatividade resulta da interação de um sistema composto por três elementos: uma cultura que combina regras simbólicas, uma pessoa que traz a novidade para a o domínio simbólico e um campo de especialistas que reconhecem e validam a inovação. Todos os três são necessários para uma ideia, produto ou descoberta criativa existir (CSIKSZENTMIHALYI, 2007).

O modelo da Perspectiva Sistêmica da Criatividade considera o contexto cultural como uma comunidade de pessoas que compartilham diferentes formas de pensar e agir, que aprendem umas com as outras e replicam suas ações. As culturas são compreendidas como sistemas de domínios inter-relacionados, que se diferem em seus procedimentos técnicos, tipos de conhecimento e crenças. O domínio no qual o indivíduo atua trata de um corpo de conhecimentos associados a uma determinada área, como, por exemplo, a matemática ou a música (ALENCAR, FLEITH, 2003). Por isso, novamente o papel do conhecimento é ressaltado, a fim de permitir que o indivíduo promova intervenções criativas na área (CSIKSZENTMIHALYI, 2007). Mas, a para que uma nova ideia seja de fato considerada criativa, é que seja validada dentro de determinada cultura, representada pelos campos, grupos de especialistas em determinada área que têm o papel de avaliar uma nova ideia como criativa (ALENCAR, FLEITH, 2003; CSIKSZENTMIHALYI, 2007).

A fim de compreender melhor a importância do ambiente para a criatividade, outros estudos e modelos surgiram a partir da psicologia e, sobretudo, da administração, explorando o contexto organizacional com o objetivo de aprimorar práticas de gestão e impulsionar a criatividade e a inovação nas empresas.

O modelo inicial de Amabile (1983) foi aprimorado para a Teoria Componencial da Criatividade e Inovação Organizacional. Segundo essa teoria, a criatividade do indivíduo, mesmo em uma equipe, é resultado da expertise, das habilidades criativas e da motivação intrínseca. Por sua vez, a criatividade do indivíduo ou equipe é influenciada pelo ambiente de trabalho, que envolve: (i) a motivação organizacional; (ii) a disponibilidade de recursos; e (iii) as práticas de gestão (AMABILE, 1997). 
De acordo com esse modelo, a motivação organizacional é o componente básico para estimular a criatividade e propiciar a inovação nas empresas. A orientação em direção à inovação deve partir dos altos níveis de gestão, mas todos os níveis hierárquicos são importantes para comunicar e interpretar essa orientação. As práticas de gestão e os recursos disponíveis são fatores que afetam a motivação organizacional e dos indivíduos (em grupos e equipes) (AMABILE, 1997).

Outra fonte relevante é o Modelo Interacionista da Criatividade Organizacional (WOODMAN et al, 1993), pelo qual a criatividade organizacional está relacionada com o comportamento criativo individual, que compreende uma complexa interação entre o indivíduo e a situação. Nesta teoria, a criatividade em grupo é uma função das entradas do comportamento criativo individual, da interação entre os indivíduos envolvidos, das características do grupo, de seus processos (abordagens para resolver o problema), além das influências contextuais. A criatividade em grupo é sobretudo influenciada pela composição da equipe (sua diversidade), as características do grupo (tamanho, coesão), dos processos realizados em conjunto (estratégias de resolução de problemas e processos de comunicação), e das influências contextuais da organização (WOODMAN et al, 1983).

Outra teoria com uma perspectiva baseada nas interações é a Teoria da Ação Criativa em Domínios Sociais Múltiplos (FORD, 1996). Nesta proposta, o foco está sobre os domínios específicos. Esses domínios e seus campos de conhecimento, com suas regras e práticas, incluem grupos, organizações, ambientes institucionais e mercados (FORD, 1996). Além do domínio especifico, há outros aspectos do contexto organizacional que influenciam a criatividade dos indivíduos e destes em seus grupos de trabalho. Um destes é a liderança, que deve incluir feedbacks construtivos, incorporar metas de desenvolvimento vinculadas à criatividade e gerenciar os recursos adequadamente para a realização das tarefas (AGARS et al, 2012). Klijn e Tomic (2010) também sugerem como principais elementos da criatividade organizacional: a liderança; as influências culturais; a disponibilidade de recursos; políticas de recompensa; a missão e a estratégia organizacional; estrutura e tecnologia.

Essas teorias e modelos auxiliam a compreensão dos fatores que interferem na criatividade, no pensamento criativo individual e nos processos criativos em grupos. Os indivíduos trabalham em um ambiente (acadêmico, organizacional, cultural) e, por isso, o papel dos grupos é muito importante com relação ao estímulo ou à inibição da criatividade individual e, por consequência, com relação aos resultados do processo criativo (SHALLEY et al, 2004).

\subsection{Grupos Criativos}

Um grupo criativo pode ser definido como um sistema coletivo em que operam diferentes personalidades, no qual se espera haver um clima favorável, com liderança positiva e uma missão compartilhada. De acordo com o modelo de Woodman et al (1983) visto anteriormente, a composição da equipe, as características do grupo e os processos realizados em conjunto são determinantes para a criatividade do grupo.

Gilson e Shalley (2004) enfatizam dois fatores relevantes para a criatividade em grupo: a tarefa projetual e a interdependência dos membros da equipe. A tarefa impacta o processo criativo na medida em que os indivíduos percebem que a criatividade é um componente importante para a realização do trabalho. A interdependência trata da confiança dos sujeitos uns com relação aos outros, fazendo 
com que se sintam motivados a realizar as tarefas e a ajudar a equipe a alcançar os resultados esperados (GILSON, SHALLEY, 2004).

Além da questão ligada à confiança e socialização entre os membros, os processos realizados em grupo também são fatores que afetam a criatividade, incluindo a comunicação, o engajamento, a administração de conflitos. De acordo com Taggar (2002), equipes com processos bem desenvolvidos, envolvendo a colaboração do grupo, a síntese de ideias e o estabelecimento de metas em conjunto, possuem melhores resultados. Porém, quando os grupos possuem baixa incidência nesses processos, a criatividade individual pode ser neutralizada (TAGGAR, 2002).

Esta relação da criatividade com os processos em grupo é também tratada sob um enfoque cognitivo, a partir do conceito de modelos mentais compartilhados enquanto uma variável importante para o desempenho das equipes de trabalho. Os modelos mentais se referem ao conhecimento que é processado por todos os membros da equipe sobre a tarefa. São estruturas cognitivas que influenciam o comportamento, a tomada de decisão e permitem que os sujeitos antecipem as reações de outros indivíduos, ajustem seu comportamento e avaliem cursos de ação alternativos (MUMFORD et al, 2001; NEUMAN et al, 2006).

Os modelos mentais compartilhados podem auxiliar a equipe a canalizar a geração de ideias nos fatos que são relevantes ao problema, além de facilitarem a comunicação e integração dos indivíduos (MUMFORD et al, 2001). Ademais, também podem incluir conhecimentos sobre o processo. Quando os membros de uma equipe buscam trabalhar juntos para resolver determinado problema e estruturar os procedimentos necessários (por exemplo, aplicando métodos e técnicas), o desempenho tende a ser melhor (NEUMAN et al, 2006).

Com isso, conclui-se que a criatividade em processos em grupo é resultado da interação dos indivíduos, com suas características pessoais, e de sua motivação intrínseca, em uma relação de interdependência e confiança entre os membros da equipe. Por sua vez, as características da formação do grupo, como tamanho, coesão e diversidade dos sujeitos, os modelos mentais compartilhados, abrangendo os processos e os conhecimentos, e a comunicação entre a equipe são essenciais para a fluência da criatividade dos indivíduos, do processo criativo em equipe e para a motivação intrínseca. Por fim, também é preciso considerar que os grupos estão inseridos em um ambiente social e que os aspectos relativos à esse afetarão todos os demais componentes.

\section{MODELO DOS FATORES DA CRIATIVIDADE: AMBIENTE, GRUPO E INDIVÍDUO}

Com base na revisão de literatura realizada, desenvolveu-se um modelo (Figura 1) com a síntese dos principais fatores que afetam a criatividade e suas interações, incluindo a motivação intrínseca e extrínseca. Esta visualização dos fatores mais importantes ligados ao indivíduo, aos grupos e ao contexto ambiental é relevante para compreender os diversos aspectos que interferem no processo criativo, no pensamento dos indivíduos e nos resultados desse processo.

A motivação é um aspecto central, que permeia todas as esferas - indivíduos, grupos e contexto ambiental - em uma influência recíproca. Ou seja, a motivação individual interfere nos grupos e no ambiente, bem como os fatores ambientais e de composição da equipe afetam a motivação individual, e por sua vez o processo 
criativo, o pensamento individual e, com isso, o resultado criativo (AMABILE, 1983; 1997; CHAKRABARTI, 2011; CSIKSZENTMIHALYI, 2007; TSCHIMMEL, 2010).

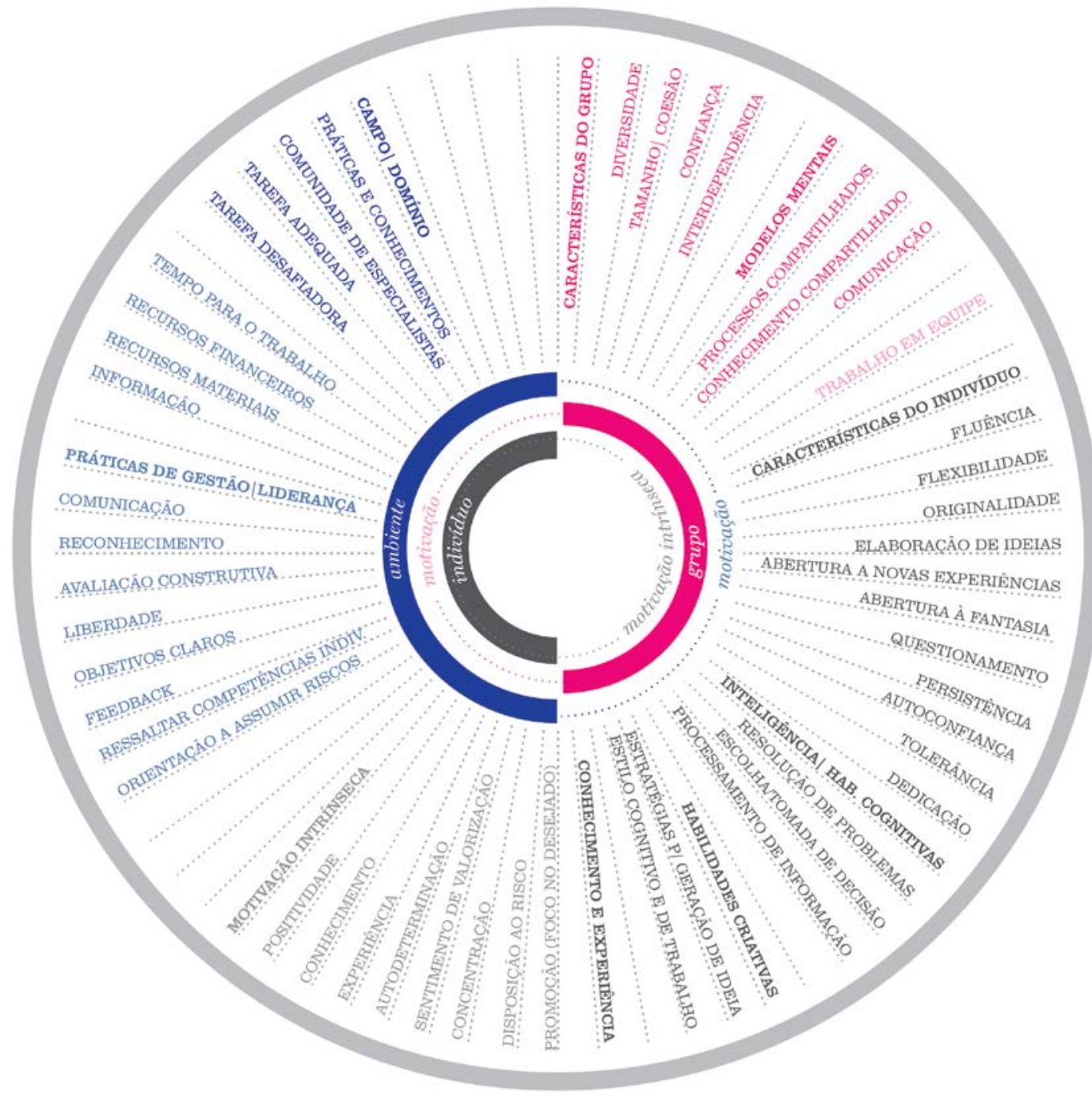

Figura 1: modelo dos fatores relacionados à criatividade: indivíduo, grupo e contexto.

Elaborado pelos autores

Com relação ao indivíduo, é preciso considerar as suas características pessoais, essenciais (fluência, flexibilidade; originalidade; e elaboração de ideias) e desejáveis (persistência; autoconfiança; tolerância; dedicação; questionamento; abertura a novas experiências; e abertura a fantasias). Além disso, há a inteligência e as habilidades cognitivas, que incluem o pensamento para a resolução de problemas, a capacidade de tomada de decisão e o processamento e organização da informação. Ainda com relação ao indivíduo, há as habilidades criativas, relativas ao processo, que incluem a capacidade para elaborar estratégias para geração de ideias, o estilo cognitivo e de trabalho. Por fim, é preciso ter em conta o conhecimento mínimo necessário para a tarefa e a experiência do sujeito em relação à atividade (ALENCAR, FLEITH, 2003; FEIST, BARRON, 2003; GUILFORD, 1967; KLAUSEN, 2010; KNELLER, 1978; KOWALTOWSKI et al, 2010; MARÍN IBAÑEZ, DE LA TORRE, 1991; MACKINNON, 1965; STERNBERG, 2012). 
Atrelada a esses fatores está a motivação intrínseca, que é afetada e influencia características pessoais, como positividade, autodeterminação, o sentimento de valorização, a capacidade de concentração e a disposição ao risco. Além disso, o conhecimento e a experiência são importantes fatores motivacionais, pois podem fazer o indivíduo se sentir apto para realizar a tarefa, desde que não restrinja a sua curiosidade e o desafio relacionado à atividade. Também é importante manter o foco na promoção, ou seja, no resultado final que é desejado, eliminando os aspectos negativos. Isso pode reduzir emoções e sentimentos negativos e bloqueios emocionais, (AMABILE, 1983; 1997; CHAKRABARTI, 2011; CSIKSZENTMIHALYI, 1988; 2007; HIGGINS, 1998; KRÖPER et al, 2011).

Os indivíduos quando trabalham em grupos (de projeto, neste caso), serão afetados pelas características do grupo, como a diversidade entre os membros, o tamanho e a coesão entre a equipe, além da confiança e a interdependência positiva entre os sujeitos. É importante considerar também os conhecimentos e processos que são compartilhados, formando modelos mentais comuns que podem contribuir para o processo coletivo de criação, bem como a comunicação entre o grupo. Esses aspectos irão afetar a motivação para o trabalho em equipe, que por sua vez irá influenciar e ser influenciada pela motivação intrínseca dos indivíduos (BISSOLA et al, 2014; GILSON, SHALLEY, 2004; MUMFORD et al, 2001; NEUMAN et al, 2006; TAGGAR, 2002).

Os grupos criativos estão inseridos em um ambiente social - organizacional, acadêmico, ou outro - que inclui os aspectos relativos ao campo/domínio específico em questão. Aqui são relevantes as práticas e os conhecimentos validados na área, a comunidade de especialistas do campo, além das características da própria tarefa, que deve ser adequada aos recursos e a capacidade dos indivíduos, ao mesmo tempo em que seja desafiadora o bastante para estimulá-los. Também são aspectos importantes o tempo adequado para o trabalho, os recursos materiais, financeiros e a informação disponível para o projeto. Ainda no contexto ambiental, as práticas de gestão e a liderança são muito importantes para a criatividade, incluindo a comunicação aberta, o reconhecimento de competências e esforços, ressaltar as competências individuais, a avaliação construtiva, a liberdade para novas ideias, feedbacks constantes, a clareza nos objetivos a serem atingidos e a orientação a assumir riscos. Todos esses aspectos serão determinantes para a motivação que o ambiente oferecerá para os grupos e seus indivíduos, também em uma relação de influência recíproca com a motivação intrínseca (AGARS et al, 2012; ALENCAR, FLEITH, 2003; AMABILE, 1983, 1997; CSIKSZENTMIHALYI, 1988; FORD, 1996; STRERNBERG, 1988; WOODMAN et al, 1993).

Com base na grande diversidade de estudos relacionados à criatividade, a partir do resumo dessas teorias apresentadas nesse artigo e sintetizadas no modelo (Figura 1), é possível perceber que as teorias mais atuais estão centradas em uma visão holística, sistêmica, contextual e que envolve multi-níveis, compreendendo diversos fatores que influenciam o a criatividade dos indivíduos, em grupos, equipes e instituições, seja no âmbito organizacional ou acadêmico. Esses fatores compreendem desde o nível cognitivo até o contexto social e cultural. Entretanto, embora em teoria se compreenda a visão sistêmica da criatividade, correlacionar todos os fatores que interferem no processo criativo não é uma tarefa fácil na prática de projeto, tendo em vista que são muitas variáveis que podem interferir e, ainda, que se modificam conforme a circunstância e os atores envolvidos no processo. 
Assim, este modelo foi desenvolvido com a finalidade de mapear os principais aspectos que podem afetar a criatividade nessa perspectiva contextual, que considera o indivíduo como um dos componentes do processo. Ter esta compreensão e visualização desses aspectos é importante para o desenvolvimento de processos, métodos, técnicas e métricas que permitam interferir em determinado fator, considerando a sua inter-relação com os demais, ainda que possa ser difícil trabalhar em todos ao mesmo tempo. $O$ importante nesta identificação é que permite, dentro da diversidade de variáveis, conhecer e selecionar os aspectos críticos em determinado contexto projetual, para então atuar nestes fatores e em suas relações mais próximas.

\section{CONSIDERAÇÕES FINAIS}

A criatividade enquanto competência do indivíduo é um dos tópicos mais explorados ao longo do tempo, incluindo seus traços de personalidade, intelecto e comportamento. Compreende aspectos motivacionais e comportamentais, sendo que a cognição constitui-se em um dos principais fatores com relação à criatividade (ALENCAR, FLEITH, 2003; AMABILE, 1997; FEIST, BARRON, 2003; GUILFORD, 1967; KNELLER, 1978; KOWALTOWSKI et al, 2010; MARÍN IBAÑEZ, DE LA TORRE, 1991).

A visão contextual da criatividade (AMABILE, 1983, 1997; CKIKSZENTMIHAYI, 1988, 2007; STERNBERG, 1988; STERNBERG, LUBART, 1991; 1995), incluindo as abordagens voltadas à criatividade organizacional (WOODMAN et al, 1993, FORD, 1996. MUMFORD et al, 2001) traz diversos fatores que se inter-relacionam e influenciam a criatividade nos indivíduos, como o trabalho em grupos e equipes, liderança, recursos disponíveis, a motivação organizacional, a natureza da atividade e o campo de conhecimento.

Conforme apresentado, a criatividade projetual, enquanto uma capacidade sistêmica, envolve um processo de criação, que inclui tanto o processo cognitivo do indivíduo quanto os processos de projeto, de comunicação e compartilhamento de conhecimento, influenciados pelos fatores contextuais. Além da capacidade cognitiva dos indivíduos, as relações sistêmicas que ocorrem são determinantes para a criatividade (TSCHIMMEL, 2010). Essas relações compreendem diversos componentes, conforme os fatores da criatividade apresentados no modelo desenvolvido.

O modelo apresentado, assim, é um constructo do que é relacionado pelas principais teorias que tratam da criatividade no indivíduo e no contexto. Evidentemente, não é um conjunto fechado de fatores, pois essas variáveis podem ser desmembradas em outros elementos e novos aspectos podem ser acrescentados. Mas, devido ao grande número de aspectos que são relacionados à criatividade, de acordo com as diferentes áreas e teorias, buscou-se àqueles mais recorrentes e relevantes. Todavia, entende-se que, de acordo com o contexto em questão, por exemplo, organizacional ou acadêmico, e com o enfoque desejado, como cognitivo, afetivo ou social, esses aspectos devem ser expandidos e detalhados.

Esta primeira versão foi desenvolvida a fim de conter os componentes iniciais para o desenvolvimento de um framework que auxilie o pensamento criativo de designers, quando trabalham em grupos de projeto, visando facilitar a geração de ideias e soluções. Para tanto, é importante que esta versão seja cruzada com novos dados, coletados não apenas de revisão de literatura, mas também a partir da prática projetual. Espera-se, assim, que a revisão e o modelo apresentados neste artigo sirvam como fonte para a ampliação de estudos como esse e para trabalhos futuros 
relacionados ao entendimento e ao desenvolvimento de modelos e ferramentas que facilitem o processo criativo em design.

\section{AGRADECIMENTO}

O presente trabalho foi realizado com apoio da CAPES, Coordenação de Aperfeiçoamento de Pessoal de Nível Superior - Brasil.

\section{REFERÊNCIAS}

AGARS, M. D. et al. Fostering individual creativity through organizational context: a review of recent research and recommendations for organizational leaders. In: MUMFORD, M. D. (org). Handbook of Organizational Creativity. San Diego: Academic Press, 2012.

ALENCAR, E. M. L. S.; FLEITH, D. S. Criatividade: múltiplas perspectivas. 3 ed. Brasília: Editora Universidade de Brasília, 2003.

AMABILE, T. M. Social psychology of creativity: A componential conceptualization. Journal of Personality and Social Psychology, 1983, 45, p.997-1013.

AMABILE, T. M. Motivating creativity in organizations: on doing what you love and loving what you do. California Management Review, vol 40, n1, 1997, pp. 38-58.

BISSOLA, R. et al. Enhancing the creative performance of new product teams: an organizational configurational approach. Journal of Product Innovation Management, n31, v2, 2014, pp. 375-391.

CHAKRABARTI, A. Motivation as a Major Direction for Design Creativity Research. In: TAURA, T,; NAGAI, Y (Eds). Design Creativity 2010. London: Springer, 2011, pp. 49-56.

CROWE, E.; HIGGINS, E. T. Regulatory focus and strategic inclinations: Promotion and prevention in decision making. Organizational behavior and human decision processes, 69 (2), 1998, pp.117-132.

CSIKSZENTMIHALYI, M. Society, culture and person: a systems view of creativity. In: STERNBERG, R. J. (org). The nature of creativity. New York: Cambridge University Press, 1988.

CSIKSZENTMIHALYI, M. Creativity: flow and the psychology of discovery and invention. Harper Collings Publishers: Australia, 2007.

FEIST, Gregory J.; BARRON, Frank X. Predicting creativity from early to late adulthood: Intellect, potential, and personality. Journal of research in personality, v. 37, n. 2, p. 6288, 2003.

FORD, Cameron M. A theory of individual creative action in multiple social domains. Academy of Management review, v. 21, n. 4, p. 1112-1142, 1996.

GUILFORD, J. P. The Nature of Human Intelligence. New York: McGraw-Hill, 1967.

GILSON, L. L.; SHALLEY, C. E. A little creativity goes a long way: an examination of team's engagement in creative process. Journal of Management, n30, v4, 2004, pp.453-470.

HENNESSEY, B. A; AMABILE, T. M. Creativity. Annual Review of Psychology, vol. 61, pp. 569-598, 2010.

HIGGINS, E. T. Promotion and Prevention: Regulatory focus as a motivational principle. In M. P. Zanna (Ed.). Advances in Experimental Psychology, 30, 1998, pp.1-46 
KLAUSEN, S. H. The notion of creativity revisited: a philosophical perspective on creativity research. Creativity Research Journal, 22, 4, 2010, pp.347-360.

KLIJN, M.; TOMIC, W. A review of creativity within organizations from a psychological perspective. Journal of Management Development, vol. 29, n 4, 2010, pp.-322-343.

KNELLER, G. F. Arte e Ciência da Criatividade. 2 ed. São Paulo: IBRASA, 1978.

KOWALTOWSKI, D. C. C. K. et al. A criatividade no processo de projeto. IN: PETRECHE, J. R. D.; FABRÍCIO, M. M. (Org). O Processo de Projeto em Arquitetura. São Paulo: Oficina de Textos, 2011.

KRÖPPER, M. et al. Interrelations between Motivation, Creativity and Emotions in Design Thinking Processes. In: TAURA, T,; NAGAI, Y (Eds). Design Creativity 2010. London: Springer, 2011, pp. 97-104.

LUBART, T. Psicologia da Criatividade. Porto Alegre: Grupo A. 2007.

MACKINNON, D. W. Personality and the realism of the creative potential. American Psychologist, 20, 1965, pp. 273-281.

MARÍN IBAÑEZ, R.; DE LA TORRE, S. Manual de la creatividad: aplicaciones educativas. Barcelona: Vicens Vives, 1991.

MUMFORD, M. S. et al. Tradeoffs between ideas and structure: individual versus group performance in creative problem solving. Journal of Creative Behavior, v.35, n.1., 2001, pp. 1-23.

NEUMAN, A. et al. A framework for measuring team mental models in design. In: Proceedings of the 9th International Design Conference, Croatia, 2006, pp.1491-1498.

SARKAR, P.; CHAKRABARTI, A. The effect of representation of triggers on design outcomes. Artificial Intelligence for Engineerign Design, Analysis and Manufacturing, 22, 2008, pp.101-116

SAUNDERS, R.; Gero J.S. Artificial creativity: A synthetic approach to the study of creative behaviour. In: GERO, J.S.; MAHER, M.L. (Ed). Computational and Cognitive Models of Creative Design, Vol.V. Sydney, Australia: University of Sydney, Key Centre of Design Computing and Cognition, 2001, pp. 113-139.

SHALLEY, C. E. et al. The effects of personal and contextual characteristics on creativity: where should we go from here? Journal of Management, n30, v6, 2004, pp. 933-958.

STERNBERG, R.J. A three-facet model creativity. In: STERNBERG, R.J (Org.), The nature of creativity. Contemporary psychological perspectives. Cambridge: Cambridge University Press, 1988.

STERNBERG, R. J. Psicologia Cognitiva. São Paulo: Cengage Learning, 2012.

STERNBERG. R.J.; LUBART, T.I. An investment theory of creativity and its development. Human Development, 34, 1991, pp. 1-31.

STERNBERG. R.J.; LUBART, T.I. Defying the crowd. Cultivating creativity in a culture of conformity. New York, The Free Press, 1995.

TAGGAR, S. Individual creativity and group ability to utilize individual creative resources: a multilevel model. Academy of Management Journal, v. 45, n. 2, pp. 315-330, 2002.

TSCHIMMEL, K. C. Sapiens e Demens no pensamento criativo do design. Tese (Doutorado em Design) - Universidade de Aveiro, Departamento de Comunicação e Arte, Aveiro, 2010. 
WOODMAN, R. W.; SAWYER, J. E.; GRIFFIN, R. W. Toward a theory of Organizational creativity. Academy of Management Review, 1993, Vol. 18, No, 2, pp. 293-321. 